\title{
MECANISMOS DE DESGASTE DE CORPOS MOEDORES EM MOINHOS DE BOLAS
}

Eduardo Roveri ${ }^{1}$ Arthur Pinto Chaves ${ }^{2}$

\section{Resumo}

A moagem dos minérios é o componente de custo de produção mais importante na produção dos metais correspondentes, constituindo parcela significativa do consumo do material metálico de corpos moedores e revestimentos. Faz-se rápida revisão dos modelos mais aceitos para a previsão do desgaste metálico. Ressalta-se o fato de que o processo não é apenas mecânico, como a maioria das aproximações faz crer, mas também eletroquímico, uma vez que, na polpa de moagem, existem espécies iônicas capazes de acarretar a corrosão do metal. A ação conjunta de abrasão e corrosão tem efeito sinérgico de modo que a velocidade do processo conjunto é muito maior que a soma das duas velocidades individualizadas. Foram ensaiados dois concentrados de minério de ferro de diferentes teores de sílica, usando bolas marcadas, variando a composição do material das bolas e o pH da polpa de moagem. Mediu-se a redução do diâmetro das bolas em função do tempo, obtendo-se como resultado uma taxa de desgaste média, por hora, para os dois tipos de bolas estudados. Os resultados permitem identificar e quantificar claramente os componentes de abrasão e corrosão sobre o resultado final.

Palavras-chave: Corpos moedores; Desgaste; Abrasão; Corrosão.

\section{MECHANISMS OF CHARGE WEAR IN BALL MILLS}

\begin{abstract}
The grinding of ores is an important cost item in the production of metals. Metal wear is a major part of it. This paper reviews the most accepted models for wear during grinding. This process, in fact, is not just a mechanical one as most of the models induce, but also electrochemical as in the slurry inside the mill there are ionic species able to carry out metal corrosion. The joint action of abrasion and corrosion has a synergetic effect and the rate of the joint process is greater than the sum of the rates of the two individual processes. A series of bench tests with two iron ore concentrates of different silica grades, using marked balls, varying metal composition and slurry $\mathrm{pH}$, was performed. Wear rates were calculated from diameter reduction as a function of time. Results make able to identify and measure the abrasion and corrosion components on the final result.
\end{abstract}

Key words: Grinding balls; Wear; Abrasion; Corrosion.

\section{INTRODUÇÃO}

Em operações de beneficiamento de concentrados, a operação unitária de moagem pode chegar a representar $40 \%$ dos custos totais da operação, como com concentrados de cobre, por exemplo. Deste total, parte fundamental é constituída pelos custos envolvidos no desgaste da carga moedora e revestimentos.

Apesar da ênfase dada à contribuição do componente abrasivo do desgaste, deve-se lembrar que toda polpa mineral possui íons em solução, que, dependendo de sua natureza, podem adicionar um componente de desgaste corrosivo, que tem ação sinérgica com o componente abrasivo. Isto é, a velocidade de desgaste do processo conjunto - corrosão + abrasão - é muito maior que a soma das velocidades singelas por corrosão e por abrasão. Cabe ressaltar que as águas brasileiras costumam ser de caráter ácido, o que acaba valendo como regra para as regiões da Bacia Amazônica e do Quadrilátero Ferrífero, em Minas Gerais.

Siriani ${ }^{(1)}$ explica que a presença de minerais duros, como o quartzo, aumenta sobremaneira a dureza do material e lembra que esse mineral, ao se romper com fratura concoidal, apresenta arestas vivas que causariam

\footnotetext{
'Estudante de Engenharia de Minas, Departamento de Engenharia de Minas e de Petróleo, Escola Politécnica da Universidade de São Paulo - EPUSP, Av. Prof. Mello Moraes, 2373, Cidade Universitária, Cep 05508-900, São Paulo, SP, Brasil. E-mail: eduardo.roveri@usp.br

${ }^{2}$ Engenheiro Metalurgista EPUSP, Professor titular (aposentado), Departamento de Engenharia de Minas e de Petróleo, Escola Politécnica da Universidade de São Paulo - EPUSP, Av. Prof. Mello Moraes, 2373, Cidade Universitária, Cep 05508-900, São Paulo, SP, Brasil.

E-mail: apchaves@usp.br
} 
concentração de tensões localizadas em áreas muito pequenas. Assim, justifica sua maior penetrabilidade nos corpos moedores, riscando-os e abreviando sua vida útil.

Albertin $^{(2)}$ descreve 0 mecanismo de desgaste como uma partícula suficientemente dura atacando uma superfície em um ângulo favorável e conseguindo atuar como uma ferramenta de corte, retirando "cavacos" (microcorte). Esta ação seria geralmente acompanhada por grande deformação plástica, observando-se acúmulo de material deslocado à frente do sulco e lateralmente, bem como deformação subsuperficial. Assim, passagens sucessivas de grãos abrasivos repetem ciclicamente esses deslocamentos, levando à remoção do material por fadiga de baixo ciclo, configurando um modelo da interação entre os grãos de quartzo e o material constituinte das bolas.

Chaves e Peres ${ }^{(3)}$ enumeram diferentes mecanismos de desgaste abrasivo:

- desgaste por sulcamento (gouging abrasion), que ocorre com partículas mais grosseiras que, quando impactam a superfície metálica de baixa dureza com velocidades médias a altas, arrancam pedaços macroscópicos de metal (altas tensões e alto impacto);

- riscamento e erosão, que ocorrem com partículas menores, cujo impacto sobre a superfície é menor (baixas tensões e baixo impacto). O movimento das partículas sobre e contra a superfície vai riscando-a, polindo-a e erodindo-a;

- riscamento e moagem (lixamento), característico de altas tensões e de impacto médio e baixo, é um comportamento intermediário entre os dois anteriores.

Ainda Chaves e Peres ${ }^{(3)}$ descrevem as seguintes maneiras pelas quais bolas de um moinho se desgastam:

- riscamento: partículas duras riscam as superfície das bolas, levantando metal paralelamente à direção do seu movimento, criando uma saliência lateral, que será erodida preferencialmente;

- indentação ou mordida: grãos duros, prensados entre duas bolas, indentam a superfície de uma delas, empurrando o metal para os lados, gerando uma cratera, inicialmente sem remoção do material, mas criando uma saliência lateral como no riscamento já descrito, que também será erodida preferencialmente;

- sulcamento: partículas duras e pesadas rasgam a superfície, arrancando metal;

- desgaste metal contra metal devido ao contato entre as superfícies de duas bolas, sem minério entre elas;

- pitting corrosion: caracteriza-se por furos profundos devidos à corrosão do metal, pela formação de pares galvânicos dentro da bola ou entre a bola e a polpa;

- lascamento (spalling): decorre do trincamento da bola a partir de defeitos de fundição (rechupes) ou de moldagem. A bola vai sendo lascada sucessivamente, em camadas, como uma cebola.
A corrosão metálica é a transformação de um material metálico ou liga metálica pela sua interação química ou eletroquímica num meio agressivo. Trata-se de um processo eletroquímico em que o ferro metálico $\left(\mathrm{Fe}^{0}\right)$ cede elétrons e recebe íons do oxigênio da polpa, tornando-o oxidado $\left(\mathrm{Fe}^{3+}\right)$. É um processo traiçoeiro porque lento, quase imperceptível, muitas vezes acaba negligenciado ou esquecido.

Gentil( ${ }^{(4)}$ lembra que, para muitas ligas de ferro, pode ocorrer a passivação do metal quando em meio alcalino. Esta seria uma alternativa para se tentar diminuir a ação corrosiva, pela introdução de algum álcali, como a soda. Já a corrosão é aumentada pela presença de íons cloreto e de oxigênio dissolvidos na água. Ele recomenda a desaeração da água a ser utilizada em operações industriais.

O processo corrosivo é acelerado pela abrasão: o produto da corrosão é um material oxidado, facilmente removível pela ação mecânica da rolagem entre as bolas, intensificada pela presença de minerais abrasivos. A sua remoção expõe uma superfície fresca de metal, quimicamente ativa e pronta para ser corroída rapidamente. Deste modo, a ação conjunta torna-se extremamente rápida e danosa.

Há vários tipos de marcação de corpos moedores para acompanhar 0 seu desgaste. $\mathrm{Maia}^{(5)}$ confirma que o ensaio com bolas marcadas permite medir com boa precisão o seu consumo. No presente estudo foram utilizadas bolas com marcação feita por eletroerosão, marcas circulares que permitem, de acordo com seu número, diferenciar o tipo de bola, no caso, bolas de aço ou de FFBAC (Ferro Fundido Branco de Alto Cromo - 30\% Cr). Entretanto, como mostra a Figura I, apenas a aparência permite essa distinção: as de aço mais escurecidas e com traços de pitting corrosion, e as de FFBAC, mais claras, e aparentemente preservadas de ataques corrosivos.
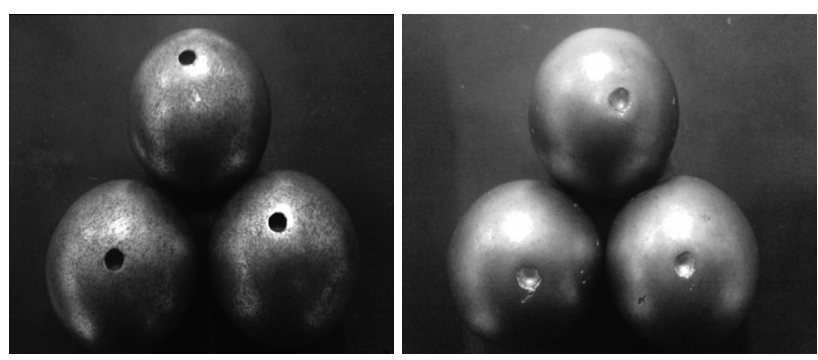

Figura I. Bolas marcadas de aço e de FFBAC.

\section{I.I Teoria Volumétrica do Desgaste de Bolas}

Essa teoria afirma que a razão de desgaste de uma bola é proporcional à sua massa, portanto ao seu volume, ou seja, ao cubo de seu diâmetro. Sua origem está na idéia de que a maioria dos eventos de cominuição decorra dos 
mecanismos de impacto. Seria, de modo geral, mais aplicável a alimentações de distribuições granulométricas mais amplas, nas quais haja predominância de material mais grosso, no qual a cominuição ocorra predominantemente por mecanismo de impacto. ${ }^{(5)}$

\section{I.2 Teoria Superficial de Desgaste}

Ainda, segundo Maia, ${ }^{(5)}$ a maioria dos eventos de cominuição deve-se à abrasão bola-partícula-bola. Então, a razão de desgaste é proporcional à área da superfície da bola, ou seja, ao quadrado do diâmetro.

Segundo Azzaroni, ${ }^{(6)}$ a redução do diâmetro de uma bola é constante e uniforme em relação ao tempo de operação ou à produção do moinho:

$$
\frac{\mathrm{df}}{\mathrm{dt}}=-\mathrm{k}
$$

Com o tempo, tem-se:

$$
\frac{\mathrm{df}}{\mathrm{dt}}=-\mathrm{k} \theta^{\mathrm{n}}
$$

onde $\mathrm{n}$ é função das características da moagem, distribuição da dureza ao longo do raio do corpo moedor e outras variáveis, podendo variar de um moinho para outro.

Assim, para a avaliação das taxas de desgaste da carga moedora, seria necessário determinar tão somente, mas com precisão, a variação da massa do corpo moedor, desde sua entrada até sua saída do moinho. Conhecida esta variação, por meio da massa específica do material calcula-se a variação de volume, e, em sequência, de diâmetro, qual seria a taxa de desgaste para um dado corpo moedor.

\section{MATERIAIS E MÉTODOS}

Este trabalho mediu o desgaste ocorrido em um moinho de bancada, usando bolas de aço e bolas de FFBAC e dois tipos de concentrado de ferro, tipo pellet feed, originários de Minas Gerais, sendo o primeiro denominado de Baixa Sílica (BS) e o outro, de Alta Sílica (AS), respectivamente, contendo em torno de $\mathrm{I}, 8 \%$ e $6 \% \mathrm{SiO}_{2}$.

Primeiramente, as amostras dos dois concentrados foram homogeneizadas em pilha alongada e retiradas alíquotas para análise química. Uma vez confirmados os teores de $\mathrm{Fe}$ e $\mathrm{SiO}_{2}$ em cada tipo de concentrado, iniciaram-se os ensaios de moagem por batelada. A Tabela I mostra a análise química dos concentrados e a Tabela 2, a sua distribuição granulométrica.

$O$ ensaio de moagem foi conduzido colocando bolas, minério e água até preencher $40 \%$ do volume interno do moinho e ajustar a porcentagem de sólidos na polpa em $87 \%$ em peso. O moinho utilizado é cilíndrico, com dimensões internas de $200 \times 250 \mathrm{~mm}$ e gira a 73 RPM.
Tabela I. Análise química dos concentrados (\%)

\begin{tabular}{crr}
\hline Elemento & \multicolumn{1}{c}{ AS } & \multicolumn{1}{c}{ BS } \\
\hline $\mathrm{Fe}$ & 67,30 & 69,00 \\
$\mathrm{SiO}_{2}$ & 6,03 & $\mathrm{I}, 78$ \\
$\mathrm{Al}_{2} \mathrm{O}_{3}$ & $0,7 \mathrm{I}$ & 0,12 \\
$\mathrm{P}$ & $<0,0 \mathrm{I}$ & 0,01 \\
$\mathrm{Mn}$ & 0,28 & 0,10 \\
$\mathrm{TiO}_{2}$ & $<0,10$ & $<0,10$ \\
$\mathrm{CaO}$ & $<0,10$ & $<0,10$ \\
$\mathrm{MgO}$ & $0,3 \mathrm{I}$ & $<0,10$ \\
$\mathrm{Na}_{2} \mathrm{O}$ & $<0,10$ & $<0,10$ \\
$\mathrm{~K}_{2} \mathrm{O}$ & $<0,10$ & $<0,10$ \\
$\mathrm{P.F}$ & 0,45 & 0,92 \\
\hline
\end{tabular}

Tabela 2. Distribuição granulométrica da alimentação do moinho (\% retida acumulada)

\begin{tabular}{clcc}
\hline Malha Tyler & $\mathbf{m m}$ & AS & BS \\
\hline 4 & 4,8 & - & 0,82 \\
6 & 3,4 & 0,13 & 1,14 \\
9 & 2,0 & 0,34 & 1,73 \\
14 & 1,2 & 1,60 & 2,45 \\
28 & 0,600 & 9,71 & 3,85 \\
65 & 0,210 & 32,84 & 8,15 \\
100 & 0,150 & 45,31 & 11,94 \\
150 & 0,105 & 57,57 & 21,00 \\
200 & 0,075 & 68,57 & 33,72 \\
325 & 0,044 & 85,68 & 63,11 \\
-325 & - & 100,00 & 100,00 \\
\hline
\end{tabular}

Para a realização do ensaio, foram utilizadas bolas marcadas. Para completar a carga do moinho, foram utilizadas bolas não-marcadas, denominadas bolas de enchimento. Foram utilizadas 15 bolas marcadas de aço e 15 de ferro fundido. Após a pesagem de cada lote de bolas, foi completada a massa de carga moedora. Registra-se que foi necessário determinar as massas com duas casas decimais para conferir precisão as medidas de desgaste. No início de cada ensaio, as bolas foram submetidas a uma rodada de moagem, a seco, com areia, para retirar eventuais protuberâncias ou áreas oxidadas e ainda limpar o material.

O ensaio de desgaste, de oito horas, consistiu nas seguintes etapas: pesagem dos corpos moedores marcados e anotação da massa individual de cada corpo moedor; pesagem da carga de enchimento; pesagem da alíquota de concentrado de ferro; medida do volume de água necessário; colocação do concentrado, dos corpos moedores e da água dentro do moinho; acionamento do moinho pelo período de uma hora, ao término do qual o moinho é aberto, as bolas são retiradas e lavadas com lavador de alta pressão; a polpa restante nas paredes e no fundo do moinho é retirada; carrega-se o moinho nova- 
mente com a mesma massa de concentrado de ferro, água e corpos moedores; aciona-se novamente o moinho e, decorrida uma hora, repete-se a sequência para mais uma rodada de moagem em batelada.

Transcorridas as oito horas do ensaio, as bolas eram retiradas do moinho e lavadas com água sob alta pressão. Em seguida, as bolas eram submetidas a duas etapas de imersão em lavadora de ultrassom, cada uma com duração de 15 minutos. Na primeira imersão, utilizava-se água como solução de limpeza, já na segunda, acetona. Dessa forma, assegurava-se a retirada das gotículas de água eventualmente aderidas à superfície das bolas, evitando-se assim a corrosão precoce sobre a superfície das bolas. Por último, as bolas eram colocadas sob lâmpadas incandescentes de $1.000 \mathrm{~W}$, pelo período de 10 minutos, para secagem final. Finalizadas integralmente tais etapas, as bolas eram, então, conduzidas à pesagem em balança.

\section{TRABALHO EXPERIMENTAL E RESULTADOS}

O método consiste em medir a variação de diâmetro de cada bola, comparável com os valores de referência da literatura. Para isso, foram admitidas como esferas as bolas de moinho utilizadas. Em posse dos valores de massa específica e de massa medida, obteve-se o diâmetro equivalente. Os valores utilizados de massa específica foram de $7,5 \mathrm{~g} / \mathrm{cm}^{3}$ para as bolas de FFBAC, e de $7,85 \mathrm{~g} / \mathrm{cm}^{3}$, para as bolas de aço. Desta forma, a taxa de desgaste para cada bola pode ser calculada, sendo representada pela a variação de diâmetro de cada bola. Para o cálculo da taxa média horária, é obtida a média aritmética entre todas as bolas marcadas, componentes do lote, levando-se em consideração a duração do ensaio, em horas:

$$
\phi_{\text {equivalente }}=\sqrt[3]{8 \cdot\left(\frac{3 \cdot \mathrm{m}}{4 \cdot \pi \cdot \rho}\right)}
$$

Onde:

- m: massa da bola;

- $\rho$ : massa específica da liga da bola;

taxa média de desgaste $=\frac{\phi_{\text {eq }} \text { inicial }-\phi_{\text {eq }} \text { final }}{\Delta \mathrm{t}}$

Onde:

- фeq inicial: diâmetro equivalente no início do ensaio;

- фeq final: diâmetro equivalente ao término do ensaio;

- $\Delta \mathrm{t}$ : intervalo de tempo de ensaio.

A programação experimental executada é mostrada na Tabela 3. A água foi obtida da rede de abastecimento local.

A Tabela 4 exemplifica o cálculo da taxa de desgaste.

A Tabela 5 mostra, como resultados, as taxas médias de desgaste obtidas.

Tabela 3. Condições experimentais - efeito da abrasão

\begin{tabular}{cccc}
\hline Ensaio & Material & Concentrado & $\mathbf{p H}$ \\
\hline I & aço & BS & 8,5 \\
2 & FFBAC & BS & 8,5 \\
3 & aço & AS & 8,5 \\
4 & FFBAC & AS & 8,5 \\
\hline
\end{tabular}

Tabela 4. Cálculo do desgaste das bolas de aço com concentrado AS em pH 8,5

\begin{tabular}{|c|c|c|c|c|c|c|}
\hline Bola no & $\begin{array}{c}\text { Alimentação } \\
\text { massa (g) }\end{array}$ & $\varnothing$ equiv. (mm) & Bola $n^{\circ}$ & $\begin{array}{c}\text { Pesagem } 8 \text { h } \\
\text { massa (g) }\end{array}$ & $\varnothing$ equiv. $(\mathrm{mm})$ & Desgaste $(\mathrm{mm})$ \\
\hline I & I I7,84 & 30,61 & I & 117,58 & 30,58 & 0,023 \\
\hline 2 & 118,03 & 30,62 & 2 & 117,75 & 30,60 & 0,024 \\
\hline 3 & I | 8,05 & 30,62 & 3 & I | 7,86 & 30,61 & 0,016 \\
\hline 4 & I | 8,22 & 30,64 & 4 & I 17,94 & 30,61 & 0,024 \\
\hline 5 & I I8,26 & 30,64 & 5 & I I7,97 & 30,62 & 0,025 \\
\hline 6 & I | 8,54 & 30,67 & 6 & 118,26 & 30,64 & 0,024 \\
\hline 7 & 118,96 & 30,70 & 7 & 118,68 & 30,68 & 0,024 \\
\hline 8 & I |9,07 & 30,71 & 8 & I |8,77 & 30,69 & 0,026 \\
\hline 9 & 119,08 & 30,71 & 9 & || $8,8 \mid$ & 30,69 & 0,023 \\
\hline 10 & 119,27 & 30,73 & 10 & I I8,85 & 30,69 & 0,036 \\
\hline II & $1 \mid 9,27$ & 30,73 & II & I | 8,97 & 30,70 & 0,026 \\
\hline 12 & 119,28 & 30,73 & 12 & I I8,98 & 30,70 & 0,026 \\
\hline 13 & 119,45 & 30,74 & 13 & 119,14 & 30,72 & 0,027 \\
\hline 14 & 119,76 & 30,77 & 14 & 119,40 & 30,74 & 0,031 \\
\hline 15 & 122,22 & 30,98 & 15 & 121,99 & 30,96 & 0,019 \\
\hline média & 19,02 & 30,71 & média & I | 8,73 & 30,68 & 0,025 \\
\hline desvio & I,07 & 0,09 & desvio & 1,06 & 0,09 & 0,004 \\
\hline$\varnothing$ equiv. méd & & 30,71 & \multicolumn{2}{|c|}{$\varnothing$ equiv. médio (mm) } & 30,68 & \\
\hline
\end{tabular}


Tabela 5. Resultados: taxas médias de desgaste obtidas $(\mu \mathrm{m} / \mathrm{h})$

\begin{tabular}{ccc}
\hline $\begin{array}{c}\text { Taxa média de } \\
\text { desgaste }\end{array}$ & Bola de aço & $\begin{array}{c}\text { Bola de ferro } \\
\text { fundido }\end{array}$ \\
\hline Concentrado BS & 2,85 & 1,06 \\
Concentrado AS & 3,12 & 1,10 \\
\hline
\end{tabular}

Estes resultados mostram que, como esperado, o desgaste das bolas de ferro fundido é inferior ao apresentado pelas bolas de aço, além de que o desgaste obtido com o concentrado de alto teor de ślica é superior ao do concentrado de baixo teor de sílica.

Passou-se então a avaliar o efeito da corrosão sobre o desgaste. Para isto, foram realizados quatro ensaios, nos quais se variou $\circ \mathrm{pH}$ da água utilizada. Nessa etapa, foi utilizado hidróxido de sódio, em escamas, com $70 \%$ de alcalinidade, aumentando o $\mathrm{pH}$ de 8,5 para 10,5. A programação é mostrada na Tabela 6 .

A Tabela 7 mostra, como resultados, as taxas médias de desgaste obtidas.

Tabela 6. Condições experimentais - efeito da corrosão

\begin{tabular}{cccc}
\hline Ensaio & Material & Concentrado & $\mathbf{p H}$ \\
\hline 5 & aço & BS & 10,5 \\
6 & FFBAC & BS & 10,5 \\
7 & aço & AS & 10,5 \\
8 & FFBAC & AS & 10,5 \\
\hline
\end{tabular}

Tabela 7. Taxas médias de desgaste obtidas $(\mu \mathrm{m} / \mathrm{h})$ - efeito da abrasão

\begin{tabular}{ccc}
\hline $\begin{array}{c}\text { Taxa média de } \\
\text { desgaste }\end{array}$ & Bola de aço & $\begin{array}{c}\text { Bola de ferro } \\
\text { fundido }\end{array}$ \\
\hline Concentrado BS & 2,52 & 0,99 \\
Concentrado AS & 2,99 & 1,04 \\
\hline
\end{tabular}

Novamente, o desgaste das bolas de ferro fundido é menor que $\circ$ das bolas de aço e o desgaste com $\circ$ concentrado de alta sílica é maior que com o de baixa sílica. Adicionalmente, nota-se que a totalidade dos ensaios realizados em meio mais alcalino resulta em menores taxas de desgaste.

\section{DISCUSSÃO E CONCLUSÃO}

Os resultados corroboram a idéia de que a corrosão possui influência significativa sobre a taxa de desgaste das bolas. Ainda, variando $\circ \mathrm{pH}$, obtém-se a diminuição da taxa de desgaste, em especial para as bolas de aço. Isto fica evidenciado na Tabela 8 (concentrado de baixa sílica) e Tabela 9 (de alta sílica).
Tabela 8. Taxa de desgaste $(\mu \mathrm{m} / \mathrm{h})$ das ligas versus variação de $\mathrm{pH}-$ concentrado de baixo teor de sílica (BS) - efeito do material da bola

\begin{tabular}{|c|c|c|c|c|}
\hline & & \multicolumn{2}{|c|}{$\mathrm{pH}$} & \multirow[b]{2}{*}{$\begin{array}{c}\text { Taxa de desgaste } \\
\Delta(\%)\end{array}$} \\
\hline Material & $\begin{array}{l}\text { Dureza } \\
\text { (RC) }\end{array}$ & 8,50 & 10,5 & \\
\hline Aço & 49,01 & 2,85 & 2,52 & $-11,70$ \\
\hline FF & 61,50 & 1,06 & 0,99 & $-6,70$ \\
\hline \multicolumn{2}{|c|}{ Taxa de desgaste $\Delta(\%)$} & 62,82 & 59,09 & \\
\hline
\end{tabular}

Tabela 9. Taxa de desgaste $(\mu \mathrm{m} / \mathrm{h})$ das ligas versus variação de $\mathrm{pH}$ - concentrado de alto teor de sílica (AS) - efeito do material da bola

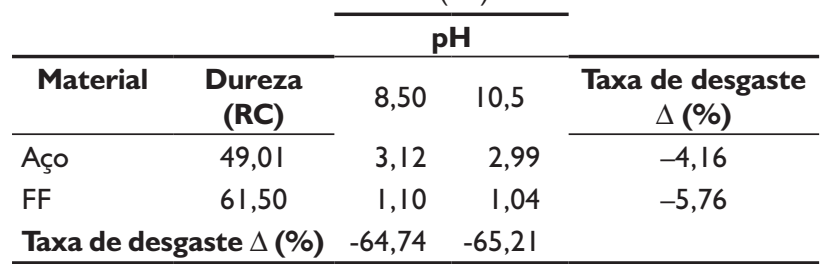

Fica evidenciado que, para a mesma bola e mesmo tipo de concentrado, quando se eleva $\circ \mathrm{pH}$ para 10,5 obtém-se a maior variação para a bola de aço, com decréscimo de $11,70 \%$ na taxa de desgaste. Também se verifica uma diminuição na taxa de desgaste para a bola FFBAC, de $6,70 \%$ na taxa de desgaste.

Fica ainda evidenciado o fato de que, para o concentrado de alto teor de sílica, a variação no $\mathrm{pH}$ não resulta numa diminuição tão significativa na taxa de desgaste nas bolas de aço $(4,16 \%)$ quanto nas bolas de $\operatorname{FFBAC}(5,76 \%)$, ressaltando o efeito abrasivo do alto teor de sílica sobre a taxa de desgaste das bolas. Outro efeito percebido é que a diferença de desempenho entre as ligas se mantém praticamente no mesmo patamar, deixando a impressão de que, para esse minério, altamente abrasivo, a diferença na taxa de corrosão parece influenciar de forma menos substancial a taxa de desgaste das bolas.

Já para o concentrado de baixo teor de sílica, o aumento do $\mathrm{pH}$ favorece a utilização das bolas de aço, enquanto que, quando se trata de concentrado de alta sílica, ainda se recomenda a utilização de bolas de FFBAC, na condição de $\mathrm{pH}$ mais baixo. Desta forma, apesar da grande diferença de desempenho quanto às taxas de desgaste, pode-se pensar em recomendar a bola de aço, para concentrado de ferro com baixo teor de sílica, desde que seja introduzida no sistema a soda cáustica.

\section{Agradecimentos}

Os autores agradecem ao IPT - Laboratório de Resíduos e Áreas Contaminadas, onde foram realizados os trabalhos experimentais, especialmente às pesquisadoras M.Sc., Sandra Lúcia de Moraes e Camila Massola Zeitune. 


\section{REFERÊNCIAS}

I SIRIANI, F. A. Características gerais de desgaste de mandíbulas em britadores. 1973. 28I f. Tese (Doutorado em Engenharia de Minas) - Escola Politécnica da Universidade de São Paulo, São Paulo, 1973.

2 ALBERTIN, E. Efeito da porcentagem de carbonetos e da microestrutura da matriz metálica sobre a resistência ao desgaste de ferros fundidos brancos de alto cromo: ensaios em moinhos de bolas. 1993. $297 \mathrm{f}$. Tese (Doutorado em Engenharia Metalúrgica) - Escola Politécnica da Universidade de São Paulo, São Paulo, 1993.

3 CHAVES, A. P.; PERES, A. E. C. Teoria e prática do tratamento de minérios. 4. ed. São Paulo: Signus, 2009. V. 3: Britagem, peneiramento e moagem.

4 GENTIL, V. Corrosão em meio aquosos. In. Corrosão. Rio de Janeiro: Guanabara Dois, 1982. Cap. 18, p. 189-95.

5 MAIA, G. S. Avaliação da qualidade dos corpos moedores para minério fosfático de Tapira - MG. 124 f. Dissertação (Mestrado em Engenharia de Minas) - Escola Politécnica da Universidade de São Paulo, São Paulo, 1994.

6 AZZARONI, E. Consideraciones acerca del desempeño de bolas para molienda y sus posibles efectos en la determinacion de la ley de desgaste. In: Simposium sobre Molienda, 5., 1987, Viña del Mar, Chile. Anales... Viña del Mar: Armco, 1987. p. I5I-2.

Recebido em: 08/04/20I I

Aceito em: 02/09/201 I 